\title{
Coarse and fine particles but not ultrafine particles in urban air trigger hospital admission for asthma in children
}

\author{
Amne Iskandar, ${ }^{1}$ Zorana Jovanovic Andersen, ${ }^{2}$ Klaus Bønnelykke, \\ Thomas Ellermann, ${ }^{3}$ Klaus Kaae Andersen, ${ }^{2}$ Hans Bisgaard ${ }^{1}$
}

\begin{abstract}
- Additional tables are published online only. To view the file please visit the journal online (http://thorax.bmj.com/ content $/ 67 / 3 . t o c$ )

${ }^{1}$ Copenhagen Prospective Studies on Asthma in Childhood, Health Sciences, University of Copenhagen and Copenhagen University Hospital, Gentofte, Copenhagen, Denmark

${ }^{2}$ Danish Cancer Society, Institute of Cancer Epidemiology, Copenhagen, Denmark

${ }^{3}$ Aarhus University, National Environmental Research Institute, Roskilde, Denmark
\end{abstract}

\section{Correspondence to}

Professor Hans Bisgaard, Copenhagen Prospective Studies on Asthma in Childhood, Health Sciences, University of Copenhagen, Copenhagen University Hospital, Ledreborg Allé 34, 2820 Gentofte Denmark;

bisgaard@copsac.com

Received 11 April 2011 Accepted 10 November 2011 Published Online First 9 December 2011

\section{ABSTRACT \\ Background Short-term exposure to air pollution can} trigger hospital admissions for asthma in children, but it is not known which components of air pollution are most important. There are no available studies on the particular effect of ultrafine particles (UFPs) on paediatric admissions for asthma.

Aim To study whether short-term exposure to air pollution is associated with hospital admissions for asthma in children. It is hypothesised that (1) the association between asthma admissions and air pollution is stronger with UFPs than with coarse $\left(\mathrm{PM}_{10}\right)$ and fine $\left(\mathrm{PM}_{2.5}\right)$ particles, nitrogen oxides $\left(\mathrm{NO}_{\mathrm{x}}\right)$ or nitrogen dioxide $\left(\mathrm{NO}_{2}\right)$; and (2) infants are more susceptible to the effects of exposure to air pollution than older children.

Method Daily counts of admissions for asthma in children aged $0-18$ years to hospitals located within a $15 \mathrm{~km}$ radius of the central fixed background urban air pollution measurement station in Copenhagen between 2001 and 2008 were extracted from the Danish National Patient Registry. A time-stratified case crossover design was applied and data were analysed using conditional logistic regression to estimate the effect of air pollution on asthma admissions.

Results A significant association was found between hospital admissions for asthma in children aged 0-18 years and $\mathrm{NO}_{\mathrm{x}}(\mathrm{OR} 1.11 ; 95 \% \mathrm{Cl} 1.05$ to 1.17$)$. $\mathrm{NO}_{2}(1.10 ; 95 \% \mathrm{Cl} 1.04$ to 1.16$), \mathrm{PM}_{10}(1.07 ; 95 \% \mathrm{Cl}$ 1.03 to 1.12 ) and $\mathrm{PM}_{2.5}(1.09 ; 95 \% \mathrm{Cl} 1.04$ to 1.13$)$; there was no association with UFPs. The association was stronger in infants than in older children for all pollutants, but no statistically significant interaction was detected. Conclusion Short-term exposure to air pollution can trigger hospital admission for asthma in children, with infants possibly being most susceptible. These effects seemed to be mediated by larger particles and trafficrelated gases, whereas UFPs showed no effect.

\section{INTRODUCTION}

Asthma is the most common chronic disease in children and the main cause of emergency room visits, ${ }^{1}$ hospital admissions ${ }^{2}$ and school absences. The incidence of childhood asthma has increased in recent decades in high-income countries, and environmental factors have gained increasing attention in attempts to understand the determinants of the asthma epidemic. ${ }^{1} 3$ Exposure to air pollution from traffic is ubiquitous in urban environments,

\section{Key messages}

What is the key question?

- Is the association between asthma admissions in children and air pollution stronger with ultrafine particles (UFPs) than with coarse and fine particles $\left(\mathrm{PM}_{10}, \mathrm{PM}_{2.5}\right)$, as suggested by animal studies and toxicology? Are infants more susceptible to the effects of exposure to air pollution than older children?

What is the bottom line?

- Exposure to air pollution triggers hospital admission for asthma in children. This effect was mediated by coarse and fine particles and traffic-related gases and not by UFPs. Infants are slightly more susceptible to the effects of air pollution, but the effects or air pollution are not limited to this group of children.

Why read on?

- This is the first epidemiological study of hospital admissions for asthma in children with data on UFPs measured in the same way as larger particles and gases. It is also the first study of a link between air pollution and hospital admissions for asthma in children which also includes infants, and thus tests for effect modification in air pollution by age.

affecting millions of people. Children are possibly more susceptible to the effects of air pollution than adults because their lungs and immune systems are developing, they inhale higher doses of air pollution relative to adults due to differences in breathing rates and patterns, and because they are generally more active in environments with high levels of pollutants when participating in sports and outdoor play. ${ }^{4}$ Chronic exposure to traffic-related air pollution in the early years of life has been suggested to contribute to the development of asthma in children, ${ }^{5-7}$ although evidence is mixed. ${ }^{8}$ Short-term exposures of several days to elevated levels of air pollution have been shown to trigger exacerbations of asthma leading to increased rates of emergency room visits ${ }^{10}$ hospital admissions for asthma, ${ }^{9}$ 11-19 wheezing symptoms ${ }^{20}$ and decreased peak expiratory flow. ${ }^{21}$ However, many aspects of the relationship between air pollution 
and childhood asthma are not fully understood, including susceptibility by age and gender as well as which pollutants are most relevant. Ultrafine particles (UFPs; particulate matter with aerodynamic diameter $<0.1 \mu \mathrm{m})$, the smallest fraction of particulate matter generated mainly by traffic, have been suggested to have particularly strong effects in the airways due to a high level of pulmonary deposition and their ability to cause inflammation and oxidative stress. ${ }^{22}$ However, epidemiological data have not been able to confirm this hypothesis, possibly due to lack of data on UFPs. ${ }^{14} 1920$

We have studied the effects on hospital admissions for asthma in children aged 0-18 years in Copenhagen, Denmark related to short-term changes in exposure to UFPs, nitrogen oxides $\left(\mathrm{NO}_{\mathrm{x}}\right)$ and particulate matter with aerodynamic diameter $\leq 10 \mu \mathrm{m}$ and $2.5 \mu \mathrm{m}\left(\mathrm{PM}_{10}\right.$ and $\left.\mathrm{PM}_{2.5}\right)$, and tested for the effect modification by age (infants $(0-1$ years), preschool children ( $2-5$ years) and school children (6-18 years)) and gender.

\section{METHODS \\ Study population}

Hospital admissions due to asthma were obtained from the Danish National Patient Registry (DNPR) which is managed by the National Board of Health. We extracted daily counts of hospital admissions for asthma (ICD-10 codes J45-J46) among children aged 0-18 years between 15 May 2001 and 31 December 2008. Asthma admissions were extracted from eight hospitals located within a $15 \mathrm{~km}$ radius (average $6 \mathrm{~km}$ ) from the central fixed background urban air pollution measurement station in Copenhagen.

\section{Air pollution and meteorology}

The pollutant and meteorological data were measured by the Danish National Environmental Research Institute at a fixed urban background measurement station (20 m height) in the centre of Copenhagen with low contributions from local streets. Main streets are located about $300 \mathrm{~m}$ west and $50 \mathrm{~m}$ east of the monitor, with 26000 and 56000 vehicles passing per working day, respectively. For the study period (May 2001 to December 2008), daily (24 h, midnight-to-midnight) mean concentrations were available for $\mathrm{PM}_{10}$ (SM200 Monitor, Opsis, Sweden), $\mathrm{PM}_{2.5}$ (TEOM Ambient Particulate Monitor, Thermo Fisher Scientific Inc., Waltham, Massachusetts, USA), nitrogen dioxide $\left(\mathrm{NO}_{2}\right)$ and $\mathrm{NO}_{\mathrm{x}}$ (M200A; API, Ry, Denmark), UFPs (Differential Mobility Particle Sizer, Roskilde, Denmark) and meteorology (dew point, wind speed, global radiation), with missing data on days with equipment malfunctions. Although the total numbers of particles included particles of $10-700 \mathrm{~nm}$ in diameter, we define them as UFPs in this study because particles $<100 \mathrm{~nm}$ in aerodynamic diameter (by definition, UFP) comprised more than $75 \%$ of the total concentration measurements.

\section{Study design and statistical analyses}

A case crossover design was used to assess the association between hospital admissions for asthma in children and air pollution levels in Copenhagen between May 2001 and December 2008. The case crossover design was developed to examine the association between transient short-term exposure and the risk of acute events in the case-only design. ${ }^{23}$ The design compares a subject's exposure immediately prior to the casedefining event (index time) to the same person's exposure at otherwise similar reference times (control periods), with reference and index times forming a matched case-control set. As each person serves as its own control, potential confounding for all personal characteristics is accomplished, while control for time-varying factors is accomplished by choosing a referent time close in time to the index time. We applied the time-stratified referent selection approach ${ }^{15}$ by comparing air pollution concentration on the day of hospital admission for asthma with to air pollution concentrations on other days falling on the same day of the week in the same calendar month as the asthma admission. This means that, if the index day is a Monday, then control days are the remaining Mondays in the same month that year, resulting in 3-4 reference periods. We performed conditional logistic regression separately for each pollutant, using the moving average of 5-day levels of air pollutants (mean of lag $0-4)$ as the main exposure proxy and, additionally, considered concentrations on the same day (lag 0), previous day (lag 1) and up to 4 days (lag 4 ) of the hospital admission, based on results from our previous study. ${ }^{19}$ The potential effect modification of an association between air pollution and hospital admissions for asthma by gender and three age groups (infants ( $0-1$ years), preschool children (2-5 years) and school children (6-18 years)) were evaluated by introducing interaction terms into the model and tested by the Wald test. Two-pollutant models were fitted for the 5-day moving average to examine the robustness of onepollutant association. Effects estimates were reported as OR associated with interquartile range (IOR) increases in air pollution concentration. The meteorological conditions, which may affect the risk of hospital admission for asthma as well as the levels of air pollution, were controlled by fitting the daily mean dew point, wind speed and global radiation by restricted cubic splines with three degrees of freedom for the same lag as the pollutants in the model. The natural logarithm was applied to normalise the air pollutants before the statistical analysis. Several sensitivity analyses were performed, including fitting the logistic regression model without wind speed and fitting the data with an alternative statistical model for Poisson data in time series format (ie, Generalised Additive Model (GAM)), with adjustment for meteorology and calendar time with restricted cubic splines. Only complete cases were considered in the analyses. The analyses were conducted using the software $\mathrm{R}$, Version 2.12.0.

\section{RESULTS}

A total of 8226 hospital admissions for asthma were recorded among children aged $0-18$ years in the eight study hospitals in Copenhagen between 15 May 2001 and 31 December 2008, with a mean of 2.95 admissions per day. Of the 8226 hospital admissions, 2765 (33.6\%) were for infants (0-1 years), 2892 $(35.2 \%)$ for preschool children (2-5 years) and 2569 (31.2\%) for school children (6-18 years). The majority of admissions were boys $(67.3 \%)$.

Air pollution and meteorological conditions in Copenhagen between 2001 and 2008 are shown in table 1, and the correlations between pollution and weather are shown in table E1 in the online supplement. The yearly distribution of air pollution levels and meteorological conditions are given in table E2 in the online supplement. The monthly number of asthma admissions during the study period and the monthly levels of $\mathrm{NO}_{\mathrm{x}}$ and UFPs are shown in figure 1 . The variation in hospital admissions over time showed approximately the same temporal variation as that of $\mathrm{NO}_{\mathrm{x}}$, indicating similar patterns of higher levels in winter and lower levels in summer, while the variations in UFPs did not correlate well with asthma admissions.

\section{Air pollution and risk of hospital admission for asthma}

We detected a significant positive association between hospital admissions for asthma in children and air pollution measured 
Table 1 Air pollutant levels and meteorological conditions in urban background in Copenhagen (May 2001-December 2008)

\begin{tabular}{|c|c|c|c|c|c|}
\hline & \multirow[b]{2}{*}{$\mathrm{N}^{*}$ (days) } & \multirow[b]{2}{*}{ Mean (SD) } & \multirow[b]{2}{*}{ Median (IOR) } & \multicolumn{2}{|c|}{ Percentile } \\
\hline & & & & 25th & 75th \\
\hline \multicolumn{6}{|l|}{ Air pollutant (unit) } \\
\hline $\mathrm{NO}_{\mathrm{x}}(\mathrm{ppb})$ & 2645 & $14.46(8.08)$ & $12.48(8.62)$ & 9.07 & 17.69 \\
\hline $\mathrm{NO}_{2}(\mathrm{ppb})$ & 2645 & $11.34(4.96)$ & $10.48(6.53)$ & 7.68 & 14.21 \\
\hline $\mathrm{PM}_{10}\left(\mu \mathrm{g} / \mathrm{m}^{3}\right)$ & 2569 & $26.18(12.84)$ & $23.7(13.4)$ & 17.9 & 31.3 \\
\hline $\mathrm{PM}_{2.5} \dagger\left(\mu \mathrm{g} / \mathrm{m}^{3}\right)$ & 1773 & $10.32(5.39)$ & $8.98(4.8)$ & 7.01 & 11.81 \\
\hline UFPs (particles $/ \mathrm{cm}^{3}$ ) & 1653 & $6398.24(3203.85)$ & $5839.13(3812.86)$ & 4138.22 & 7951.08 \\
\hline \multicolumn{6}{|l|}{ Meteorological factors (units) } \\
\hline Dew point $(C)$ & 2679 & $5.16(6.03)$ & $5.2(9.43)$ & 0.81 & 10.24 \\
\hline Wind speed $(\mathrm{m} / \mathrm{s})$ & 2619 & $4.13(1.49)$ & $3.89(1.99)$ & 2.99 & 4.98 \\
\hline Global radiation $\left(\mathrm{W} / \mathrm{m}^{2}\right)$ & 2679 & $116.8(97.51)$ & $95.72(162.8)$ & 26.77 & 189.57 \\
\hline
\end{tabular}

*Number of days with available measurements of pollutants.

$+\mathrm{PM}_{2.5}$ is measured with TEOM that measures about $30 \%$ too low particle mass due to evaporation of part of the particle mass inside the instrument.

as $\mathrm{NO}_{\mathrm{x}}, \mathrm{NO}_{2}, \mathrm{PM}_{10}$ and $\mathrm{PM}_{2.5}$, whereas a weak positive and non-significant association was detected with UFPs (table 2). The highest risk estimate per increase in IOR of 5-day mean air pollution levels prior to hospital admission for asthma was observed for $\mathrm{NO}_{\mathrm{x}}(1.11 ; 95 \% \mathrm{CI} 1.05$ to 1.17$)$, followed by $\mathrm{NO}_{2}$ (1.10; $95 \%$ CI 1.04 to 1.16$), \mathrm{PM}_{2.5}$ (1.09; 95\% CI 1.04 to 1.13$)$ and $\mathrm{PM}_{10}(1.07 ; 95 \% \mathrm{CI} 1.03$ to 1.12$)$. No significant effect
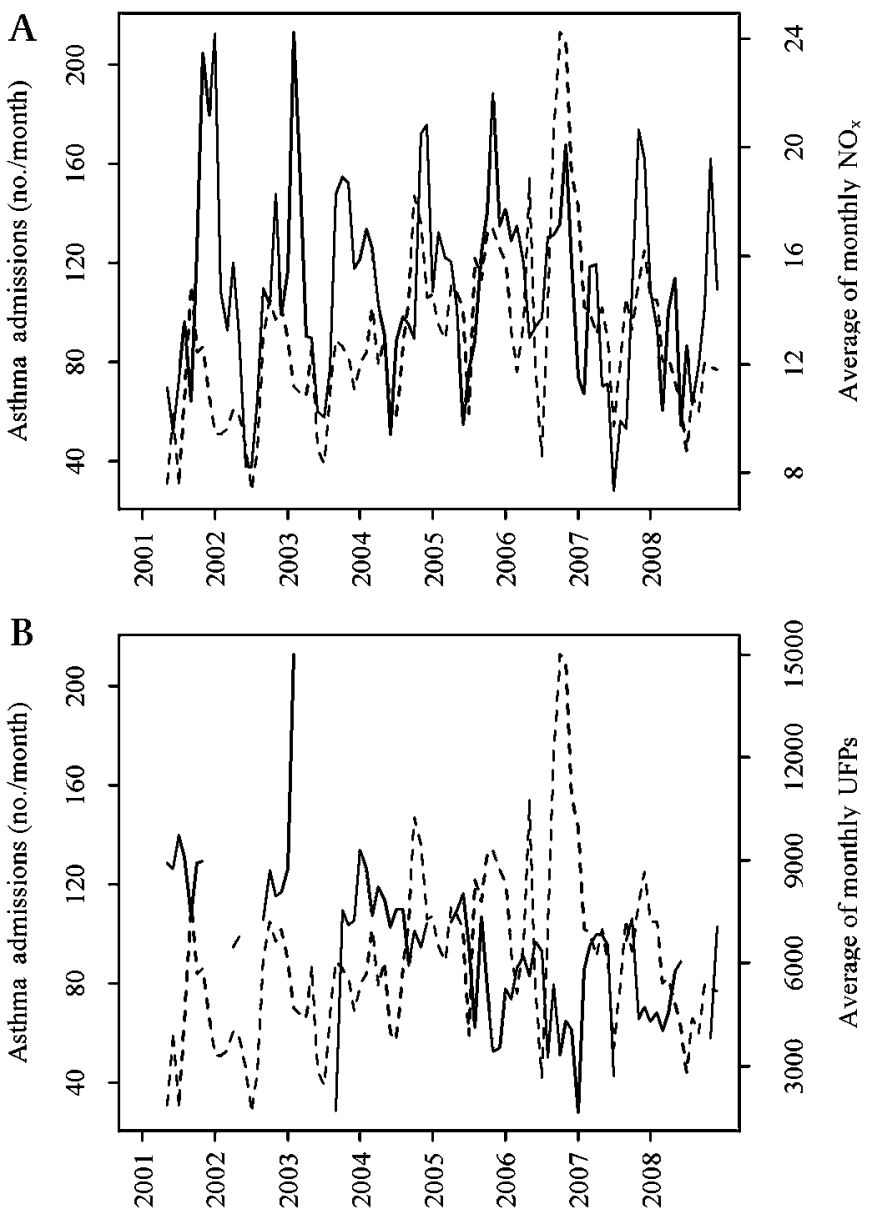

Figure 1 Number of hospitalised children with asthma during the study period (dashed lines) and average monthly air pollution measured as $(A)$ nitrogen oxides $\left(\mathrm{NO}_{\mathrm{x}}\right)$ in parts per billion and $(\mathrm{B})$ ultrafine particles (UFPs) in particles $/ \mathrm{cm}^{3}$ (solid lines). modification between air pollution levels and asthma hospital admissions were detected by age or gender (table 2).

The effect of $\mathrm{NO}_{x}$ was slightly attenuated but significant in all two-pollutant models, except for $\mathrm{NO}_{2}$ (table 3) which showed a stronger association with hospital admissions for asthma than any other pollutant. The effect of $\mathrm{NO}_{2}$ was also slightly attenuated in two-pollutant models, except for $\mathrm{PM}_{2.5}$ and UFPs. The effect of $\mathrm{PM}_{10}$ and $\mathrm{PM}_{2.5}$ was slightly attenuated in two-pollutant models, except for the effect of $\mathrm{PM}_{10}$ which was slightly enhanced in the model with $\mathrm{PM}_{2.5}$. The effect of UFPs diminished after adjustment for other pollutants.

The associations between asthma admissions and single-day levels of air pollution up to 4 days prior to admission showed statistically significant associations for lag 3 (1.09; 95\% CI 1.03 to 1.15 and $1.07 ; 95 \%$ CI 1.01 to 1.13$)$ and lag $4(1.09 ; 95 \% \mathrm{CI}$ 1.03 to 1.15 and $1.08 ; 95 \%$ CI 1.02 to 1.14 ) for $\mathrm{NO}_{x}$ and $\mathrm{NO}_{2}$, for lag 2 (1.04; 95\% CI 1.00 to 1.08) and lag 3 (1.06; 95\% CI 1.02 to 1.11) for $\mathrm{PM}_{10}$, and lag 1, lag 2 and lag 3 for $\mathrm{PM}_{2.5}$, with the strongest association at lag $3(1.09 ; 95 \%$ CI 1.04 to 1.13$)$ (figure 2). No significant association was found between any single-day levels of UFPs and asthma admission.

Higher effect estimates of exposure to $\mathrm{NO}_{\mathrm{x}}, \mathrm{NO}_{2}$, and $\mathrm{PM}_{2.5}$ were observed for hospital admissions for asthma in boys, but no statistically significant difference was detected between genders (table 2). The effects of exposure to $\mathrm{PM}_{10}$ and UFPs on hospital admissions for asthma were identical in boys and girls. We did not detect significant modification of the effect of air pollution on hospital admissions for asthma by age, but we found a stronger association in infants than in preschool and school children which was consistent for all pollutants.

We found slightly attenuated effects but statistically significant positive associations between hospital admissions for asthma and $\mathrm{NO}_{\mathrm{x}}, \mathrm{NO}_{2}, \mathrm{PM}_{2.5}$ and $\mathrm{PM}_{10}$ without wind speed in the model (see table E3 in online supplement). Similarly, when modelling hospital admissions for asthma with the Poisson GAM model, almost identical results were observed (see table E4 in online supplement).

\section{DISCUSSION}

Our study showed that ambient levels of particulates $\mathrm{PM}_{10}$ and $\mathrm{PM}_{2.5}$ and gases $\mathrm{NO}_{\mathrm{x}}$ and $\mathrm{NO}_{2}$ are associated with childhood hospital admissions for asthma in Copenhagen with an increase in the rate of admission of approximately $10 \%$ per IOR increase in air pollution levels. 
Table 2 Association* between air pollution (per IQR increase in mean 5-day (lag0-4) levels) and hospital admission for asthma in children, and effect modification by gender and age

\begin{tabular}{|c|c|c|c|c|c|}
\hline Pollutants & & Subgroup & n & OR (95\% Cl) & p Value $\dagger$ \\
\hline \multirow[t]{6}{*}{$\mathrm{NO}_{\mathrm{x}}$} & Overall & & 8155 & $1.11(1.05$ to 1.17$)$ & \\
\hline & Gender & Boys & 5508 & $1.13(1.06$ to 1.20$)$ & 0.34 \\
\hline & & Girls & 2647 & 1.08 (1.00 to 1.17$)$ & \\
\hline & Age & Infants ( $0-1$ years) & 2741 & $1.12(1.04$ to 1.21$)$ & 0.97 \\
\hline & & $\begin{array}{l}\text { Preschool children } \\
\text { ( } 2-5 \text { years) }\end{array}$ & 2873 & $1.11(1.02$ to 1.20$)$ & \\
\hline & & $\begin{array}{l}\text { School children } \\
\text { (6-18 years) }\end{array}$ & 2541 & $1.10(1.02$ to 1.20$)$ & \\
\hline \multirow[t]{6}{*}{$\mathrm{NO}_{2}$} & Overall & & 8155 & $1.10(1.04$ to 1.16$)$ & \\
\hline & Gender & Boys & 5508 & 1.11 (1.05 to 1.18$)$ & 0.44 \\
\hline & & Girls & 2647 & 1.08 (0.99 to 1.17$)$ & \\
\hline & Age & Infants ( $0-1$ years) & 2741 & $1.10(1.02$ to 1.19$)$ & 1.00 \\
\hline & & $\begin{array}{l}\text { Preschool children } \\
\text { ( } 2-5 \text { years) }\end{array}$ & 2873 & $1.10(1.02$ to 1.19$)$ & \\
\hline & & $\begin{array}{l}\text { School children } \\
\text { (6-18 years) }\end{array}$ & 2541 & $1.10(1.02$ to 1.20$)$ & \\
\hline \multirow[t]{6}{*}{$\mathrm{PM}_{10}$} & Overall & & 8155 & $1.07(1.03$ to 1.12$)$ & \\
\hline & Gender & Boys & 5508 & 1.07 (1.02 to 1.12$)$ & 0.93 \\
\hline & & Girls & 2647 & 1.07 (1.00 to 1.14$)$ & \\
\hline & Age & Infants (0-1 years) & 2741 & $1.11(1.05$ to 1.18$)$ & 0.20 \\
\hline & & $\begin{array}{l}\text { Preschool children } \\
\text { (2-5 years) }\end{array}$ & 2873 & $1.03(0.97$ to 1.10$)$ & \\
\hline & & $\begin{array}{l}\text { School children } \\
\text { (6-18 years) }\end{array}$ & 2541 & $1.07(1.00$ to 1.14$)$ & \\
\hline \multirow[t]{6}{*}{$\mathrm{PM}_{2.5}$} & Overall & Overall & 6329 & 1.09 (1.04 to 1.13$)$ & \\
\hline & Gender & Boys & 4338 & $1.10(1.05$ to 1.15$)$ & 0.33 \\
\hline & & Girls & 1991 & $1.06(0.99$ to 1.13$)$ & \\
\hline & Age & Infants (0-1 years) & 2161 & 1.11 (1.04 to 1.18$)$ & 0.62 \\
\hline & & $\begin{array}{l}\text { Preschool children } \\
\text { ( } 2-5 \text { years) }\end{array}$ & 2236 & $1.06(1.00$ to 1.13$)$ & \\
\hline & & $\begin{array}{l}\text { School children } \\
\text { (6-18 years) }\end{array}$ & 1932 & 1.09 (1.01 to 1.16$)$ & \\
\hline \multirow[t]{6}{*}{ UFPs } & Overall & Overall & 7004 & $1.06(0.98$ to 1.14$)$ & \\
\hline & Gender & Boys & 4756 & 1.06 (0.97 to 1.15$)$ & 0.93 \\
\hline & & Girls & 2248 & $1.06(0.95$ to 1.20$)$ & \\
\hline & Age & Infants ( $0-1$ years) & 2369 & $1.08(0.97$ to 1.22$)$ & 0.71 \\
\hline & & $\begin{array}{l}\text { Preschool children } \\
\text { (2-5 years) }\end{array}$ & 2464 & $1.07(0.96$ to 1.20$)$ & \\
\hline & & $\begin{array}{l}\text { School children } \\
\text { (6-18 years) }\end{array}$ & 2171 & $1.02(0.91$ to 1.15$)$ & \\
\hline
\end{tabular}

${ }^{*}$ Adjusted for dew point, wind speed and global radiation.

†Wald or likelihood ratio test for interaction.

We found no association between asthma admissions and UFPs, suggesting that adverse effects of acute exposures to air pollution on airways in children are more likely mediated by larger particles and/or gases. We previously studied similar exposures in the Copenhagen Prospective Study on Asthma Birth Cohort and found that several days of exposure to $\mathrm{NO}_{2}$ and $\mathrm{NO}_{\mathrm{x}}$ triggered episodes of 'wheezing' in infants born to mothers with asthma, ${ }^{20}$ whereas no significant association was detected with UFPs. Another Danish study of hospital admissions in school children (5-18 years) detected an association of borderline significance with $\mathrm{PM}_{2.5}$ and weaker and non-significant associations with UFPs. ${ }^{15}$ The effects associated with UFPs in both studies were similar and slightly stronger than those observed with $\mathrm{PM}_{10},{ }^{15}{ }^{20}$ but the study with hospital admissions showed that $\mathrm{PM}_{2.5}$ and not UFPs mediated the effect of particles. ${ }^{15}$ Both of these studies with follow-up until 2004 were limited by a large number of missing data on UFPs which were first available in Denmark in May 2001. In the present study on hospital admissions in children aged 0-18 years and UFP data from 2001 to 2008, we found that
Table 3 Association* between air pollution (per IQR increase in mean 5-day (lag 0-4) levels) and hospital admission for asthma in children: two-pollutant models

\begin{tabular}{|c|c|c|c|}
\hline & $\mathbf{n}$ & OR (95\% CI) & p Value \\
\hline $\mathrm{NO}_{\mathrm{x}}$ & 8155 & 1.11 (1.05 to 1.17$)$ & $<0.01$ \\
\hline Adjusted for $\mathrm{NO}_{2}$ & 8155 & $1.12(0.96$ to 1.31$)$ & 0.15 \\
\hline Adjusted for $\mathrm{PM}_{10}$ & 8155 & 1.08 (1.01 to 1.14$)$ & 0.02 \\
\hline Adjusted for $\mathrm{PM}_{2.5}$ & 6329 & $1.10(1.03$ to 1.17$)$ & $<0.01$ \\
\hline Adjusted for UFPs & 7004 & $1.10(1.03$ to 1.18$)$ & $<0.01$ \\
\hline $\mathrm{NO}_{2}$ & 8155 & $1.10(1.04$ to 1.16$)$ & $<0.01$ \\
\hline Adjusted for $\mathrm{NO}_{\mathrm{x}}$ & 8155 & $0.99(0.85$ to 1.16$)$ & 0.89 \\
\hline Adjusted for $\mathrm{PM}_{10}$ & 8155 & $1.08(1.01$ to 1.15$)$ & 0.02 \\
\hline Adjusted for $\mathrm{PM}_{2.5}$ & 6329 & $1.12(1.05$ to 1.19$)$ & $<0.01$ \\
\hline Adjusted for UFPs & 7004 & $1.13(1.05$ to 1.22$)$ & $<0.01$ \\
\hline $\mathrm{PM}_{10}$ & 8155 & 1.07 (1.03 to 1.12$)$ & $<0.01$ \\
\hline Adjusted for $\mathrm{NO}_{\mathrm{x}}$ & 8155 & 1.05 (1.00 to 1.09$)$ & 0.04 \\
\hline Adjusted for $\mathrm{NO}_{2}$ & 8155 & $1.04(1.00$ to 1.09$)$ & 0.06 \\
\hline Adjusted for $\mathrm{PM}_{2.5}$ & 6315 & $1.09(1.00$ to 1.18$)$ & 0.05 \\
\hline Adjusted for UFPs & 7004 & $1.08(1.03$ to 1.14$)$ & $<0.01$ \\
\hline $\mathrm{PM}_{2.5}$ & 6329 & 1.09 (1.04 to 1.13$)$ & $<0.01$ \\
\hline Adjusted for $\mathrm{NO}_{\mathrm{x}}$ & 6329 & 1.07 (1.02 to 1.11$)$ & $<0.01$ \\
\hline Adjusted for $\mathrm{NO}_{2}$ & 6329 & $1.06(1.02$ to 1.11$)$ & 0.01 \\
\hline Adjusted for $\mathrm{PM}_{10}$ & 6315 & $1.02(0.94$ to 1.10$)$ & 0.67 \\
\hline Adjusted for UFPs & 5692 & $1.08(1.03$ to 1.13$)$ & $<0.01$ \\
\hline UFPs & 7004 & $1.06(0.98$ to 1.14$)$ & 0.14 \\
\hline Adjusted for $\mathrm{NO}_{\mathrm{x}}$ & 7004 & $1.00(0.91$ to 1.08$)$ & 0.91 \\
\hline Adjusted for $\mathrm{NO}_{2}$ & 7004 & $0.97(0.89$ to 1.06$)$ & 0.56 \\
\hline Adjusted for $\mathrm{PM}_{10}$ & 7004 & $0.99(0.92$ to 1.08$)$ & 0.90 \\
\hline Adjusted for $\mathrm{PM}_{2.5}$ & 5692 & 0.99 (0.91 to 1.08$)$ & 0.85 \\
\hline
\end{tabular}

${ }^{*}$ Adjusted for dew point, wind speed and global radiation.

$\mathrm{IQR}$, interquartile range; $\mathrm{NO}_{\mathrm{x}}$, nitrogen oxides; $\mathrm{NO}_{2}$, nitrogen dioxide; $\mathrm{PM}_{10}, \mathrm{PM}_{2.5}$, particulate matter with aerodynamic diameter $\leq 10 \mu \mathrm{m}$ and $2.5 \mu \mathrm{m}$; UFPs, ultrafine particles.

hospital admissions for asthma were triggered by several days' exposure to larger particles $\mathrm{PM}_{10}$ and $\mathrm{PM}_{2.5}$ but not to UFPs. This finding is in agreement with a study reporting acute effects of $\mathrm{PM}_{10}$ but no effect of UFPs on peak expiratory flow in children aged 7-12 years with asthma. ${ }^{21}$ Similarly, a study in dogs failed to detect an effect of acute exposure to UFPs on airway reactivity or immune response. ${ }^{24}$ On the other hand, three studies in adults with asthma showed that respiratory effects related to air pollution were mediated by UFPs and not by larger particles. ${ }^{24} 25$ Overall, the evidence regarding the effects of UFPs on asthma is limited and conflicting, warranting more research.

The main limitation of this study is the assessment of air pollution exposure from a single background monitor as a proxy for personal exposure. Depending on the traffic intensity, wind direction and speed and building topography, the concentration of pollutants can vary considerably between sites within a city. The resulting exposure misclassifications introduce bias into our analysis which is not possible to quantify owing to lack of information on personal exposure. Furthermore, it can be argued that exposure misclassification may be larger for UFPs than for larger particles, ${ }^{15}$ which may explain the lack of association with this fraction of particulate matter. A $15 \mathrm{~km}$ radius from the central urban background measurement station represents the municipality limits of Copenhagen City with a similar population and traffic density and is assumed to be representative of air pollution levels measured at the central urban background measurement station. We have previously shown that the levels of UFPs at this site correlate well with the levels at a monitoring site at the kerbside ( $2 \mathrm{~m}$ height) of a busy street $3000 \mathrm{~m}$ away 
Figure 2 Effect estimates with $95 \% \mathrm{Cl}$ of risk of asthma exacerbation per increase in interquartile range (IOR) for (A) nitrogen oxides $\left(\mathrm{NO}_{\mathrm{x}}\right),(\mathrm{B})$ nitrogen dioxide $\left(\mathrm{NO}_{2}\right),(\mathrm{C})$ particulate matter with an aerodynamic diameter $\leq 10 \mu \mathrm{m}$ $\left(\mathrm{PM}_{10}\right)$, (D) particulate matter with an aerodynamic diameter $2.5 \mu \mathrm{m}\left(\mathrm{PM}_{2.5}\right)$ and (E) ultrafine particles (UFPs). The effect estimates are calculated for lags between zero and 4 days in air pollution.
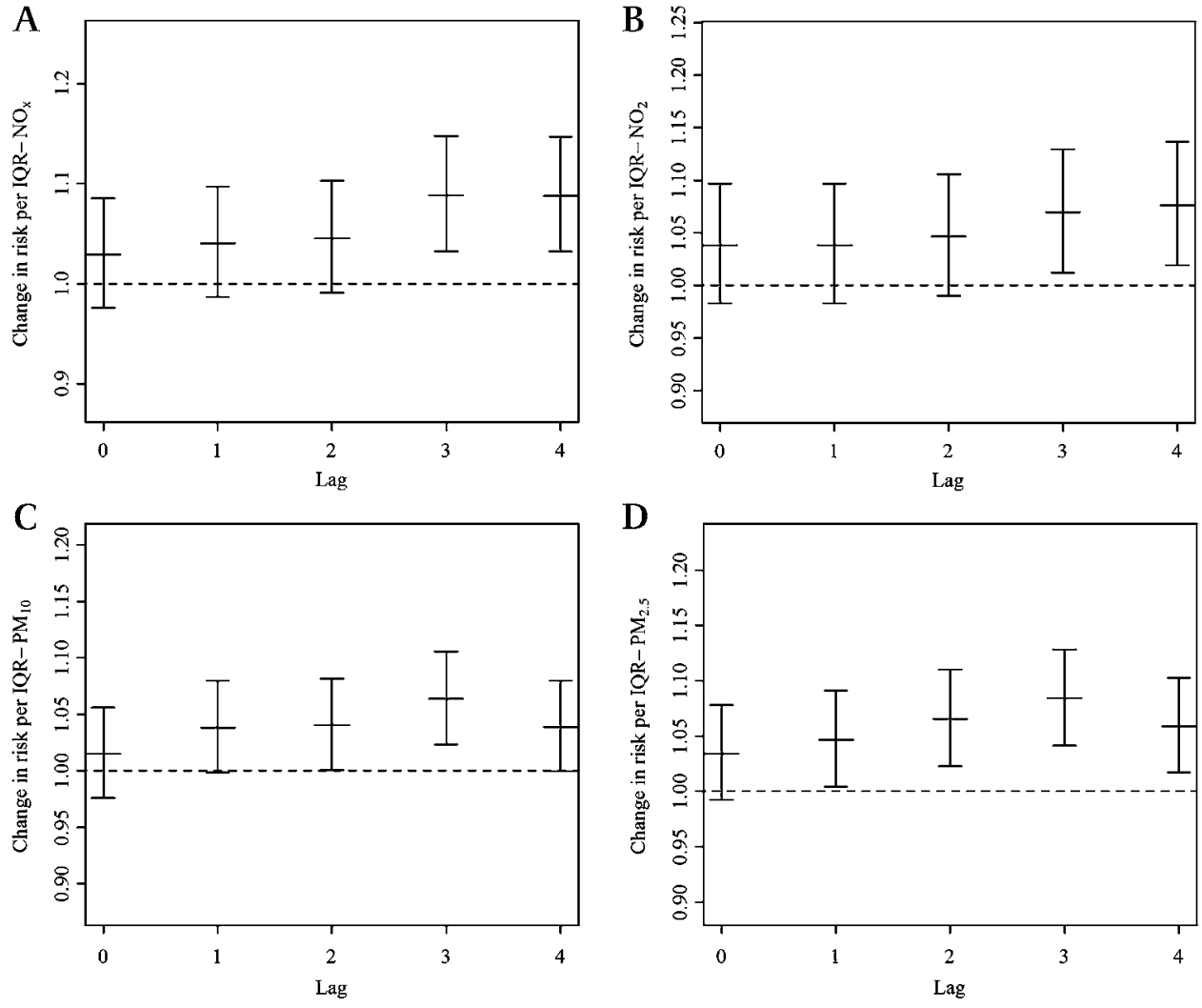

$\mathrm{D}$

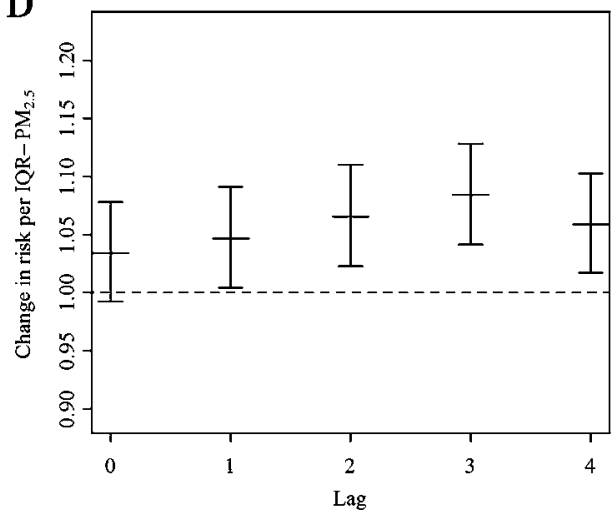

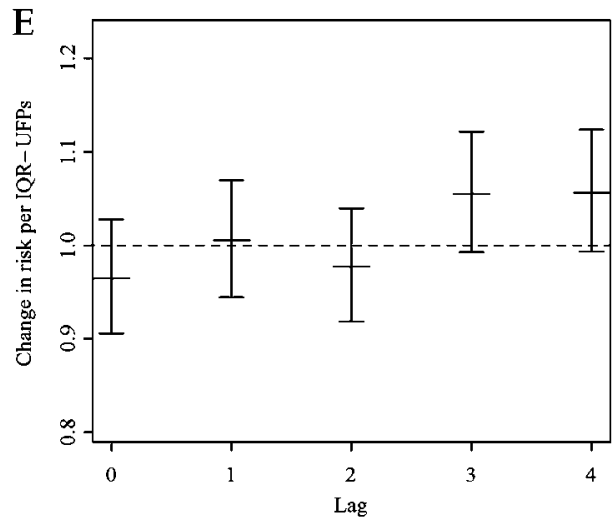

(Spearman correlation coefficient $(\mathrm{RS})=0.62$ ) and a rural monitoring site located in an agricultural area $30 \mathrm{~km}$ west of Copenhagen $(\mathrm{RS}=0.80) .{ }^{15}$ This indicates that the daily oscillations in traffic-related air pollutants on busy streets due to variation in traffic intensity, weather conditions and other factors are also reflected by urban background monitoring, and that a radius of $15 \mathrm{~km}$ from the background monitor is reasonable for the assessment of daily variations in population exposure. However, in the same study we showed that correlation between measurements of the urban background $(20 \mathrm{~m})$ and kerbside $(2 \mathrm{~m})$ monitor was lower for UFPs (RS=0.62) than for $\mathrm{PM}_{2.5}(\mathrm{RS}=0.86)$ and $\mathrm{PM}_{10}(\mathrm{RS}=0.65)$ and was lowest for the smallest fractions of UFPs, ${ }^{15}$ implying larger exposure misclassification for UFPs than for larger particles, and probably a larger bias towards zero in UFP effect estimates. We therefore cannot exclude the possibility that the lack of effect of UFPs in this study is due to differential exposure misclassification. On the other hand, we have earlier linked exposure to the same UFP data (and not with larger particles) in Copenhagen to hospital admissions for stroke in the same nine hospitals using the same epidemiological design (within $15 \mathrm{~km}$ radius from the central measurement station). ${ }^{26}$

Various factors may modify the effect of air pollution on asthma. No significant evidence for effect modification by gender or age was found. However, boys seemed to be slightly more susceptible to outdoor air pollution than girls, since the risk estimates related to $\mathrm{NO}_{\mathrm{x}}$ and $\mathrm{PM}_{2.5}$ are higher. The effects of exposure to air pollution on asthma exacerbations are suggested to be stronger in children than in adults, ${ }^{4}$ as corroborated by two studies ${ }^{17} 27$ but not confirmed by a study reporting similar effects for children (3-15 years) and adults ( $15-49$ years). ${ }^{10}$ Seasonality and associations with air pollution of asthma admissions in children have been shown to vary with age, ${ }^{12}$ showing the highest association with hospital admission rates for asthma among the youngest children ( $<2$ years). One study found a stronger association between hospital admissions for asthma and air pollution in school children (age 6-18 years) than in preschool children (age $<6$ years) ${ }^{17}$ whereas, in our earlier birth cohort study, greater effects of air pollution on wheezing were seen in infants (aged $0-1$ years) than in children 
aged $2-3$ years. ${ }^{19}$ Other studies did not assess the susceptibility to air pollution by age. ${ }^{11} 13-1619$

The strengths of our study include the long time series of daily measurements of UFP data (2001-8) which made it possible, for the first time, to investigate the association between UFPs and hospital admissions for asthma. A further strength of our study is the high quality of the hospitalisation register data derived from the DNPR. A validity study of DNPR data on asthma diagnoses in children aged 6-14 years showed that data on discharge asthma diagnoses were correct in $91 \%$ of cases, with medical records serving as the gold standard. ${ }^{28}$ Furthermore, the use of a time-stratified case crossover design minimises the effects of long-term seasonal trends and serial autocorrelation in the data and provides for full adjustment for confounders. We adjusted for possible effects of seasonal and long-time trends in air pollution levels or hospital admissions for asthma in the case crossover design by matching the air pollution level on the day of admission to hospital for asthma with the levels on the same weekday in the same month. Similarly, in time-series analyses (see online supplement), we modelled the calendar time by restricted cubic spline and thus adjusted for seasonal and long-varying trends. Finally, our findings were robust to a different modelling approach, using a time-series analysis with the GAM which used a different model of meteorology and long-term trends (see table E4 in online supplement). The risk of hospital admission for asthma using GAM was estimated to be $10 \%$ (95\% CI $5 \%$ to $16 \%$ ) per IOR increase for $\mathrm{NO}_{\mathrm{x}}$ (see table E4 in online supplement). The GAM analysis also indicated that infants were more sensitive to air pollution than preschool children and school children.

Our study also has some limitations. Caution should be taken when interpreting results from two-pollutant models with $\mathrm{PM}_{10}$ and $\mathrm{PM}_{2.5}$ (correlation coefficient $\mathrm{r}=0.93$ ) as well as $\mathrm{NO}_{\mathrm{x}}$ and $\mathrm{NO}_{2}(\mathrm{r}=0.85)$ as the effect estimates of these highly correlated variables may be artifacts of colinearity. Furthermore, the air pollution data were measured at a single background monitoring station and there were no residential or school and kindergarten addresses. Finally, we cannot exclude the possibility that the lack of effect of exposure to UFPs in this study is due to a potentially larger measurement error in UFP data than in data on larger particles and gases, and thus higher exposure misclassification for UFPs which would bias estimates towards zero.

\section{CONCLUSIONS}

Short-term exposure to ambient air pollution increases the risk of admission to hospital for asthma among children. Gases $\left(\mathrm{NO}_{\mathrm{x}}\right.$ and $\left.\mathrm{NO}_{2}\right)$ and coarse and fine particles $\left(\mathrm{PM}_{2.5}\right.$ and $\left.\mathrm{PM}_{10}\right)$ mediate the adverse effects whereas UFPs have no effect.

Funding COPSAC is funded by private and public research funds all listed on http://www.copsac.com. The Lundbeck Foundation, the Pharmacy Foundation of 1991, Augustinus Foundation, the Danish Medical Research Council and the Danish Paediatric Asthma Centre provided core support for COPSAC. Measurements of air pollution and meteorology have been funded by the Danish Environmental Protection Agency and via the Danish air quality monitoring programmes. The funding agencies did not have any role in study design, data collection and analysis, decision to publish or preparation of the manuscript.

\section{Competing interests None}

Contributors HB is the guarantor of the study and was responsible for the supervision regarding definition of asthma outcomes and interpretation of data with clinical implications for asthma. KB provided input on use of register data, asthma definitions and data interpretation. ZJA was responsible for the supervision regarding statistical modelling of air pollution exposures and use of register data. KKA was responsible for statistical supervision regarding applying case crossover and time series analyses, programming and use of relevant statistical software, and interpretation of results. TE was responsible for measurements of air pollution and meteorology. Al was responsible for data analysis, design implementation, interpretation and writing the manuscript together with ZJA. All authors contributed substantially to the analyses and interpretation of the data and provided important intellectual input and approval of the final version of the manuscript.

Provenance and peer review Not commissioned; externally peer reviewed.

\section{REFERENCES}

1. Eder W, Ege MJ, von Mutius E. The asthma epidemic. N Engl J Med 2006;355:2226-35.

2. Kocevar VS, Bisgaard $H$, Jönsson $L$, et al. Variations in pediatric asthma hospitalization rates and costs between and within Nordic countries. Chest 2004;125:1680-4.

3. Gililand FD. Outdoor air pollution, genetic susceptibility, and asthma management: opportunities for intervention to reduce the burden of asthma. Pediatrics 2009;123 (Suppl 3):168-73.

4. Bateson TF, Schwartz J. Children's response to air pollutants. J Toxicol Environ Health A 2008;71:238-43

5. Braback L, Forsberg B. Does traffic exhaust contribute to the development of asthma and allergic sensitization in children: findings from recent cohort studies. Environ Health 2009;8:17.

6. Gehring $\mathbf{U}$, Wijga $\mathrm{AH}$, Brauer $\mathrm{M}$, et al. Traffic-related air pollution and the development of asthma and allergies during the first 8 years of life. Am J Respir Crit Care Med 2010;181:596-603

7. McConnell R, Islam T, Shankardass $K$, et al. Childhood incident asthma and trafficrelated air pollution at home and school. Environ Health Perspect 2010;118:1021-6.

8. Oftedal B, Nystad W, Brunekreef B, et al. Long-term traffic-related exposures and asthma onset in schoolchildren in Oslo, Norway. Environ Health Perspect 2009;117:839-44.

9. Lierl MB, Hornung RW. Relationship of outdoor air quality to pediatric asthma exacerbations. Ann Allergy Asthma Immunol 2003;90:28-33.

10. Boutin-Forzano S, Adel N, Adel N, et al. Visits to the emergency room for asthma attacks and short-term variations in air pollution. A case-crossover study. Respiration 2004;71:134-7.

11. Erbas B, Kelly AM, Physick B, et al. Air pollution and childhood asthma emergency hospital admissions: estimating intra-city regional variations. Int J Environ Health Res 2005;15:11-20.

12. Xirasagar $\mathbf{S}$, Lin HC, Liu TC. Seasonality in pediatric asthma admissions: the role of climate and environmental factors. Eur J Pediatr 2006:165:747-52.

13. Lee SL, Wong WHS, Lau YL. Association between air pollution and asthma admission among children in Hong Kong. Clin Exp Allergy 2006;36:1138-46.

14. Tecer LH, Alagha 0 , Karaca $F$, et al. Particulate matter $\left(\mathrm{PM}_{2.5}, \mathrm{PM}_{10-2.5}\right.$, and $\left.\mathrm{PM}_{10}\right)$ and children's hospital admissions for asthma and respiratory diseases: a bidirectional case-crossover study. J Toxicol Environ Health A 2008;71:512-20.

15. Andersen ZJ, Wahlin P, Raaschou-Nielsen 0 , et al. Size distribution and total number concentration of ultrafine and accumulation mode particles and hospital admissions in children and the elderly in Copenhagen, Denmark. Occup Environ Med 2008;65:458-66

16. Giovannini M, Sala M, Riva E, et al. Hospital admissions for respiratory conditions in children and outdoor air pollution in Southwest Milan, Italy. Acta Paediatr 2010;99:1180-5

17. Robert AS, Kazuhiko I. Age-related association of fine particles and ozone with severe acute asthma in New York City. J Allergy Clin Immunol 2010;125:367-73.e5.

18. Grineski SE, Staniswalis JG, Peng Y, et al. Children's asthma hospitalizations and relative risk due to nitrogen dioxide $\left(\mathrm{NO}_{2}\right)$ : effect modification by race, ethnicity, and insurance status. Environ Res 2010;110:178-88.

19. Nastos PT, Paliatsos AG, Anthracopoulos MB, et al. Outdoor particulate matter and childhood asthma admissions in Athens, Greece: a time-series study. Environ Health 2010;9:45

20. Andersen ZJ, Loft $\mathrm{S}$, Ketzel $\mathrm{M}$, et al. Ambient air pollution triggers wheezing symptoms in infants. Thorax 2008:63:710-16.

21. Pekkanen J, Timonen KL, Ruuskanen J, et al. Effects of ultrafine and fine particles in urban air on peak expiratory flow among children with asthmatic symptoms. Environ Res 1997;74:24-33.

22. Knol AB, de Hartog JJ, Boogaard $H$, et al. Expert elicitation on ultrafine particles: likelihood of health effects and causal pathways. Part Fibre Toxicol 2009;6:19.

23. Maclure M. The case-crossover design: a method for studying transient effects on the risk of acute events. Am J Epidemiol 1991;133:144-53.

24. Penttinen $\mathbf{P}$, Timonen $\mathrm{KL}$, Tiittanen $\mathrm{P}$, et al. Ultrafine particles in urban air and respiratory health among adult asthmatics. Eur Respir J 2001;17:428-35.

25. Peters A, Wichmann HE, Tuch T, et al. Respiratory effects are associated with the number of ultrafine particles. Am J Respir Crit Care Med 1997;155:1376-83.

26. Andersen ZJ, Olsen TS, Andersen KK, et al. Association between short-term exposure to ultrafine particles and hospital admissions for stroke in Copenhagen, Denmark. Eur Heart J 2010;31:2034-40.

27. Fusco D, Forastiere $F$, Michelozzi $P$, et al. Air pollution and hospital admissions for respiratory conditions in Rome, Italy. Eur Respir J 2001;17:1143-50.

28. Moth G, Vedsted P, Schiøtz PO. National registry diagnoses agree with medical records on hospitalised asthmatic children. Acta Paediatr 2007:96:1470-3 